\section{Early morphea simulating patch-stage mycosis fungoides in two cases}

\author{
Hamid R. Ghasemi Basir, ${ }^{1}$ \\ Pedram Alirezaei, ${ }^{1}$ \\ Aliasghar Rezanejad, ${ }^{1}$ \\ Sajjad Daneshyar ${ }^{2}$ \\ ${ }^{1}$ Psoriasis Research Center; and \\ ${ }^{2}$ Student Researcher Committee, \\ Hamadan University of Medical \\ Sciences, Hamadan, Iran
}

absence of adnexal structures as well as fat trapping. However, in early-stage disease, prominent lymphoplasma cell infiltration around dermal blood vessels is very common. Fibrosis is not obvious in this early stage, and collagen bundles are swollen. These nonspecific histopathologic findings in early-stage morphea may inevitably lead to confusion with other skin disorders including cutaneous T-cell lymphoma.,3 Herein we report two unusual cases of early-stage morphea which were clinically and histologically identical to patch-stage MF.

\section{Case Report}

Morphea is a skin disorder characterized by thickening of dermis and subcutaneous tissues and loss of adnexal structures. In the early inflammatory stage of morphea, diagnostic histological findings are absent and this may lead to confusion with other inflammatory dermatoses such as mycosis fungoides (MF). We report two cases of early stage morphea mimicking patchstage of MF. Histopathologic examination of biopsies obtained early in the disease course revealed lymphocytic epidermotropism arranged in small pautrier-like collections as well as linear arrangements in dermal-epidermal junction. Additional biopsies were performed which revealed replacement of subcutaneous fat with closely packed thick collagen bundles under eccrine glands. This report points toward the fact that early stage morphea can simulate MF. Therefore additional evaluation is sometimes required for definite diagnosis.

\section{Introduction}

Morphea is a fibrosing and inflammatory disorder of dermis and subcutaneous fat that affects children and adults equaly. ${ }^{1}$ Usually no systemic involvement is being found in patients affected by morphea. Early lesions of morphea present as erythematous to violaceous patches and plaques, while full-developed lesions are asymmetric sclerotic plaques that usually measure 2 to 15 centimeters in diameter. Active lesions may have a lilac border with hypoor hyperpigmentation, while inactive lesions are often indurated with postinflammatory hyperpigmentation. In welldeveloped lesions, depositions of thick collagen bundles are seen in dermis and subcutaneous fat. A common histopathologic finding in late-stage morphea is
Two patients with erythematous to dusky violaceus patches presented to our outpatient clinic of dermatology. The first patient was a 27-year-old woman with an asymptomatic annular erythematous patch on her trunk measuring $4 \times 4$ centimeters with central poikiloderma and fine scale that first appeared three months ago. The patient was otherwise normal and physical examination was unremarkable. Skin biopsy was performed and histopathologic examination demonstrated parakeratosis, acanthosis and obvious lymphocytic epidermotropism composed of activated lymphocytes with large hyperchromatic nuclei and irregular nuclear contour that arranged in small pautrier-like collections with linear arrangement in dermal-epidermal junction (DEJ), which was suggestive for mycosis fungoides (Figure 1).

The patient had been initially treated with topical corticosteroid for 3 months without improvement, and then left untreated for 7 months. After one year, hyperpigmented sclerotic plaques appeared in the affected area (Figure 2). Another biopsy was performed at this time and histophatologic examination revealed normal appearing epidermis without lymphocytic epidermotropism, increased number of DEJ melanocytes and obvious replacement of subcutaneous fat with closely packed thick collagen bundles under eccrine glands (Figure 3). These findings were characteristic of late-stage morphea.

The second patient was a 17-year-old girl with an asymptomatic annular patch on her right arm measuring $3 \times 3$ centimeters that showed hypopigmented central zone and erythematous peripheral rim. The lesion had developed in a 2-month period (Figure 4). The patient was otherwise healthy and physical examination was normal. The first clinical differential diagno-
Correspondence: Pedram Alirezaei, Psoriasis Research Center, Farshchian Hospital, Mirzadeh Eshghi street, Hamadan, Iran.

Tel./Fax: +98.81.3827.2154.

E-mail: prc@umsha.ac.ir

Key words: Morphea; mycosis fungoides.

Contributions: all authors contributed equally.

Conflict of interest: the autors declare no potential conflict of interest.

Received or publication: 2 November 2017. Accepted for publication: 16 March 2017.

This work is licensed under a Creative Commons Attribution-NonCommercial 4.0 International License (CC BY-NC 4.0).

(C) Copyright H.R. Ghasemi Basir et al., 2018 Licensee PAGEPress, Italy

Dermatology Reports 2018; 10:7471

doi:10.4081/dr.2018.7471

sis for this case was morphea but histopathologic examination revealed parakeratosis, acanthosis and obvious lymphocytic epidermotropism composed of large lymphocytes with hyperchromatic nuclei, which were arranged in small pautrier-like collections with linear arrangement in DEJ (Figure 5). Perivascular lymphocytic infiltration was also noted in upper dermis. Because of these findings, a diagnosis of patch-stage MF was made, contrary to initial clinical presumption. One month later, another biopsy specimen was obtained and histopathologic examination demonstrated typical features of morphea including focal replacement of subcutaneous fat with closely packed thick collagen bundles (Figure 6). Mild panniculitis secondary to previous sampling was also noted. In immunohistochemistry that was done by Envision method and Dako antibody (Glostrup, Denmark), epidermotropic lymphocytes in both cases had CD4 and CD7 positive immunoreactivity without $\mathrm{CD} 8$ expression (Figure 7).

Tumor cells of mycosis fungoides frequently lack expression of CD7 and this is a useful feature that aids in differentiating reactive from neoplastic processes.

\section{Discussion}

Morphea is a clinically distinct skin disease, which primarily affects dermis and subcutaneous fat, and leads to sclerosis. ${ }^{4}$ Several variants of morphea have been rec- 
ognized. The most common variant is plaque-type morphea. This variant is characterized by slightly elevated plaques with erythematous to violaceous hue that expand centrifugally. ${ }^{5}$ Three major components that may contribute to the pathogenesis of morphea are vascular structures, activated mast cells and altered connective tissue production by fibroblasts. ${ }^{6}$ Histopathologic findings in morphea largely depend on its stage (early or late), as well as the area from which the specimen has been obtained (inflammatory border or fibrotic center). In late-stage morphea, inflammatory infiltrate wanes and finally disappears, except for some areas of subcutaneous fat. There is also extension of sclerosis into subcutaneous fat and entrapment of eccrine glands within collagen bundles. In early-stage disease and inflammatory borders, vessel walls demonstrate

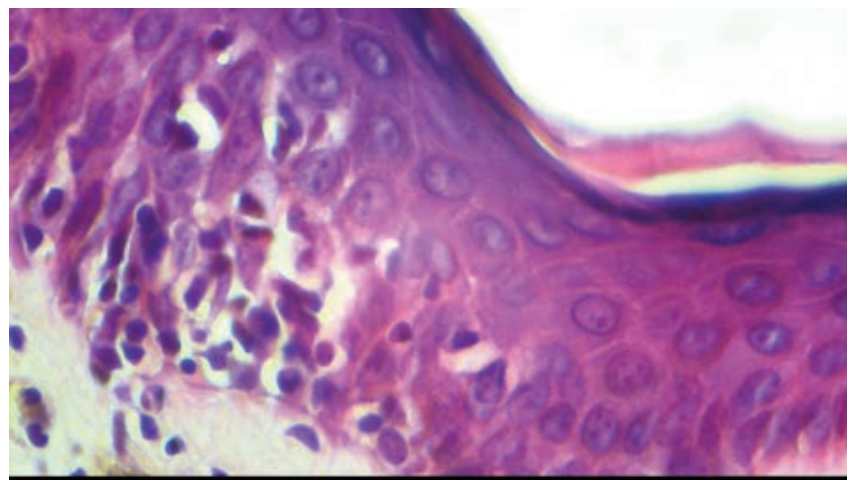

Figure 1. Early-stage morphea. Pautrier-like collections and linear arrangement of lymphocytes in dermal-epidermal junction $(\mathrm{H} \& \mathrm{E}$ $\times 40)$.

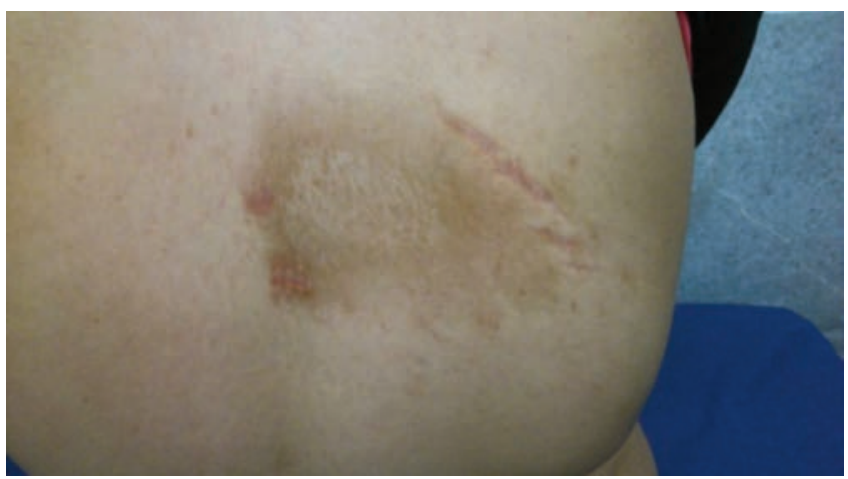

Figure 2. Clinical appearance of fully developed morphea (hyperpigmented sclerotic plaque).

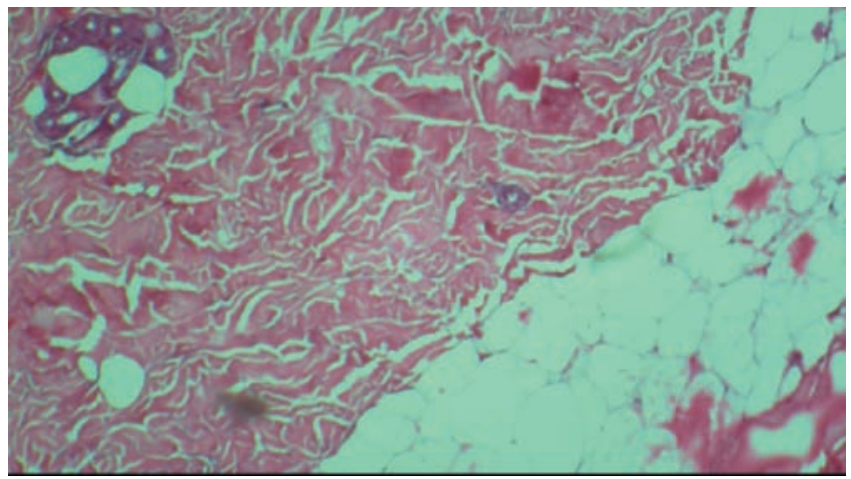

Figure 3. Late-stage morphea. Replacement of subcutaneous fat with closely packed thick collagen bundles under eccrine glands $(\mathrm{H} \& \mathrm{E} \times \mathbf{1 0})$.

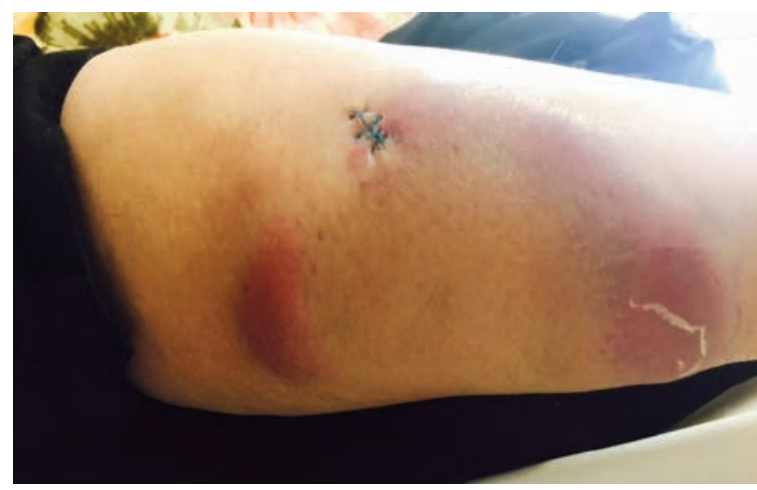

Figure 4. Clinical appearance of early-stage morphea. Hypopigmented central zone and erythematous peripheral rim.

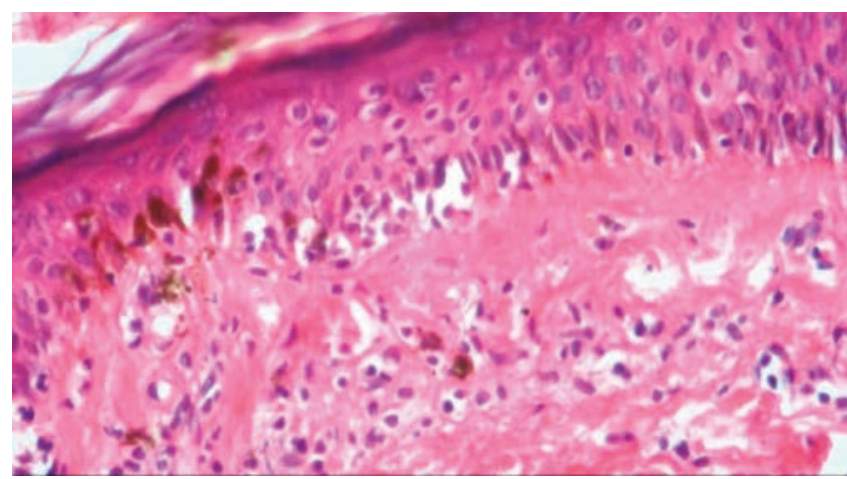

Figure 5. Early-stage morphea. Pautrier-like collections and linear arrangement of lymphocytes in dermal-epidermal junction $(\mathrm{H} \& \mathrm{E}$ $\times 20)$.

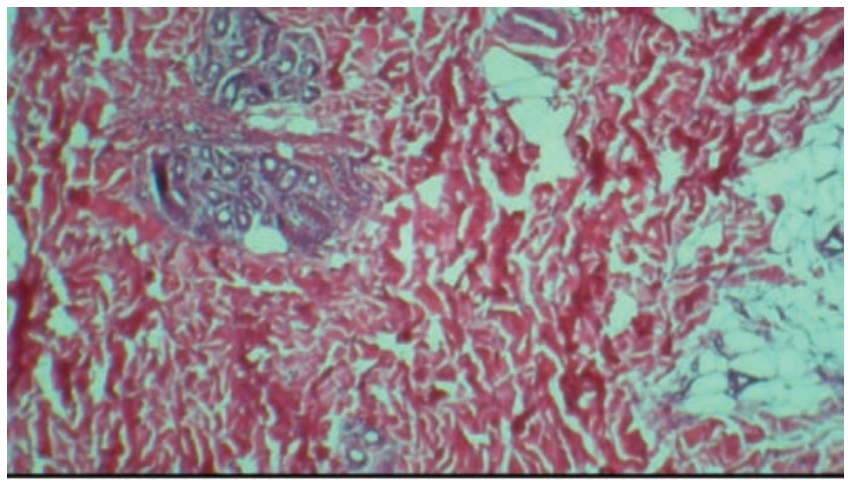

Figure 6. Late-stage morphea. Replacement of subcutaneous fat with closely packed thick collagen bundles under eccrine glands $(\mathrm{H} \& \mathrm{E} \times 10)$. 


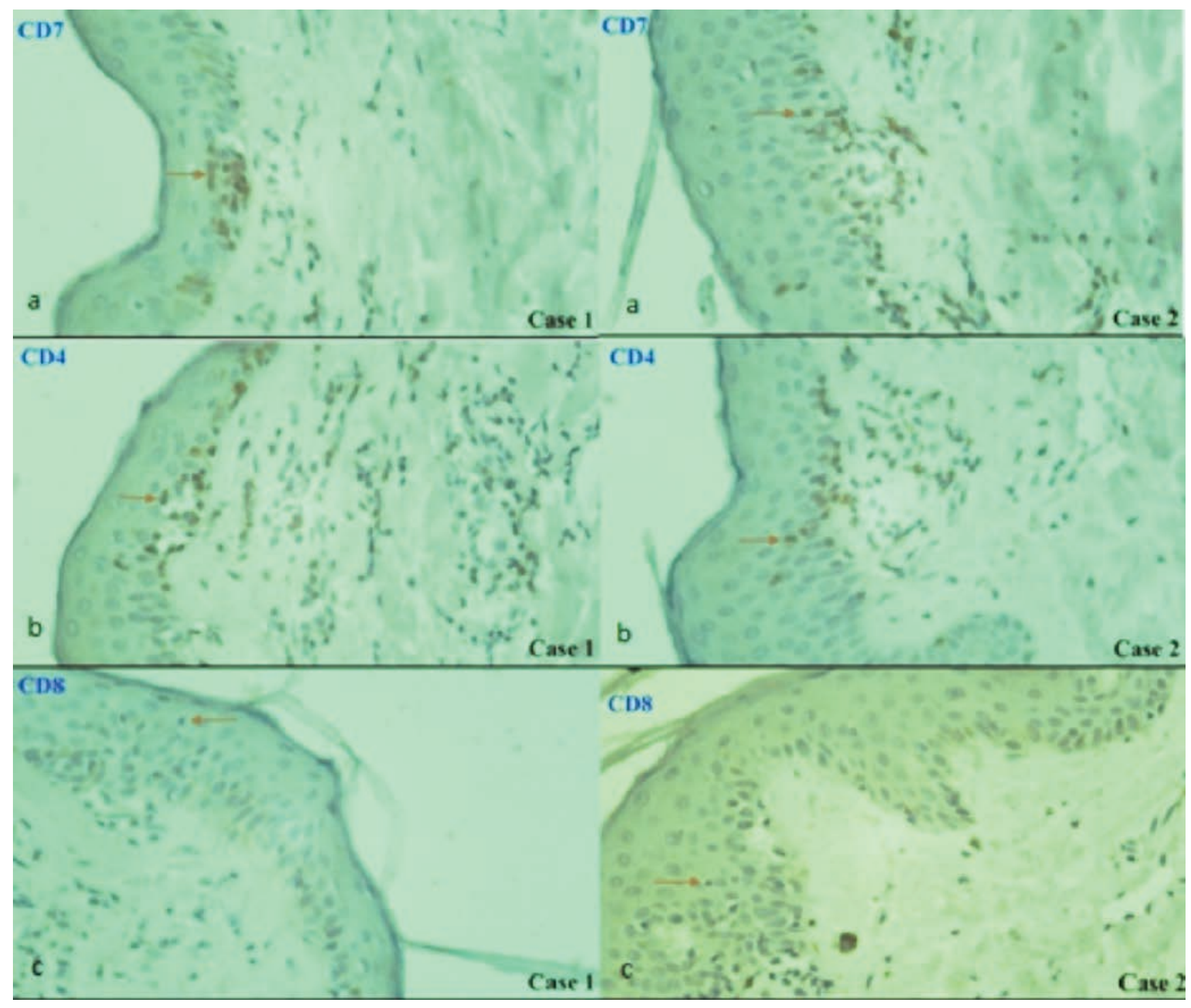

Figure 7. Immunohistochemistry: A) CD7; B) CD4 positive immunoreactivity, and C) CD8 negative immunoreactivity.

endothelial swelling and edema. Capillaries and small arterioles are surrounded by $\mathrm{CD}^{+} \mathrm{T}$ cells and sometimes eosinophils, plasma cells and mast cells. ${ }^{4}$ In this stage diagnosis may be difficult, since histopathologic findings are non-specific and mimic other skin disorders. ${ }^{7}$

In our cases initial histopatholgic findings resembled early-stage MF, but additional studies in advanced stages revealed typical features of morphea.

There are a few case reports documenting the coexistence of MF and inflammatory dermatoses. ${ }^{8}$ In one report, authors considered the possibility of coexisting MF and morphea and recommended that early morphea should be added to the list of cutaneous T-cell lymphomas. ${ }^{9}$ Coexistence of patch-stage MF and interstitial granuloma annulare has also been described. ${ }^{10,11} \mathrm{In}$ addition, systemic sclerosis has also been associated with MF. ${ }^{12}$

Immunohistochemistry is a useful method in differentiating MF from morphea. The presence of CD7 immunoreactivity has been proposed as a helpful feature that may differentiate neoplastic (MF) from reactive processes (morphea). Expression of CD7 in a suspected lesion is in favor of the diagnosis of reactive conditions such as morphea. ${ }^{13}$

\section{Conclusions}

In summary, early-stage morphea may simulate patch-stage poikilodermatous MF, both clinically and histopathologically. Therefore, it is sometimes necessary to perform additional biopsies in cases of patch-stage MF, in order to make the correct diagnosis.

\section{References}

1. Fett N, Werth VP. Update on morphea: Part I. Epidemiology, clinical presentation, and pathogenesis. J Am Acad Dermatol 2011;64:217-28.

2. Chung CG, Poligone B. Cutaneous $T$ cell lymphoma: an update on pathogenesis and systemic therapy. Curr Hematol Malignancy Rep 2015;10:46876.

3. Ghatalia P, Porter J, Wroblewski D, Carlson JA. Primary cutaneous marginal zone lymphoma associated with 
juxta $\square$ articular fibrotic nodules in a teenager. J Cutan Pathol 2013;40:47784.

4. Tratenberg M, Gutwein F, Rao V, et al. Localized scleroderma: a clinical review. Curr Rheumatol Rev 2017;13:86-92.

5. Hong JH, Kim JE, Ko JY, Ro YS. A clinicopathologic study of morphea in Korean patients. J Cutan Pathol 2015;42:929-936.

6. Claman HN. On scleroderma: mast cells, endothelial cells, and fibroblasts. JAMA 1989;262:1206-9.

7. Pimpinelli N, Olsen EA, Santucci M, et al. Defining early mycosis fungoides. J Am Acad Dermatol 2005;53:1053-63.
8. Citarella L, Massone C, Kerl H, Cerroni L. Lichen sclerosus with histopathologic features simulating early mycosis fungoides. Am J Dermatopathol 2003; 25: 463-5.

9. Fujimoto M, Basko-Plluska JL, Petronic-Rosic V, Shea CR. Early morphea simulating patch-stage mycosis fungoides. Am J Dermatopathol 2015; 37:409-12.

10. $\mathrm{Su}$ LD, Kim YH, LeBoit PE, et al. Interstitial mycosis fungoides, a variant of mycosis fungoides resembling granuloma annulare and inflammatory morphea. J Cutan Pathol 2002;29:135-41.

11. Koochek A, Fink-Puches R, Cerroni L. Coexistence of patch stage mycosis fun- goides and interstitial granuloma annulare in the same patient: a pitfall in the clinicopathologic diagnosis of mycosis fungoides. Am J Dermatopathol 2012; 34:198-202.

12. Yasuda M, Amano H, Yamanaka M, et al. Coincidental association of mycosis fungoides and occupational systemic sclerosis? J Dermatol 2008;35:21-24.

13. Ormsby A, Tubbs R, Bergfeld W, Hsi E. A new $\mathrm{Cd} 7$ paraffin reactive antibody and T- $\gamma$ Pcr monoclonality are sensitive and specific for a diagnosis of mycosis fungoides (MF). J Cutan Pathol 2000; 27:567. 